
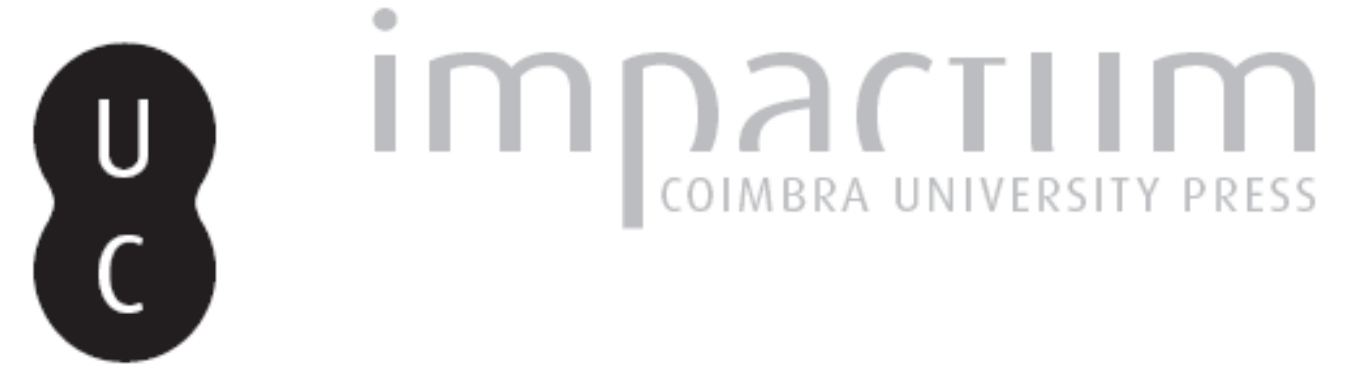

\title{
'A doença mais infamante é a de inventar histórias': o Prometeu de Kafka
}

Autor(es): $\quad$ Barbosa, Manuela

Publicado por: Associação Portuguesa de Estudos Clássicos; Instituto de Estudos
Clássicos

URL

persistente:

URI:http://hdl.handle.net/10316.2/30405

DOI:

DOI:http://dx.doi.org/10.14195/0872-2110_52_16

Accessed : $\quad$ 26-Apr-2023 16:21:12

A navegação consulta e descarregamento dos títulos inseridos nas Bibliotecas Digitais UC Digitalis, UC Pombalina e UC Impactum, pressupõem a aceitação plena e sem reservas dos Termos e Condições de Uso destas Bibliotecas Digitais, disponíveis em https://digitalis.uc.pt/pt-pt/termos.

Conforme exposto nos referidos Termos e Condições de Uso, o descarregamento de títulos de acesso restrito requer uma licença válida de autorização devendo o utilizador aceder ao(s) documento(s) a partir de um endereço de IP da instituição detentora da supramencionada licença.

Ao utilizador é apenas permitido o descarregamento para uso pessoal, pelo que o emprego do(s) título(s) descarregado(s) para outro fim, designadamente comercial, carece de autorização do respetivo autor ou editor da obra.

Na medida em que todas as obras da UC Digitalis se encontram protegidas pelo Código do Direito de Autor e Direitos Conexos e demais legislação aplicável, toda a cópia, parcial ou total, deste documento, nos casos em que é legalmente admitida, deverá conter ou fazer-se acompanhar por este aviso.

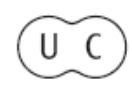




\section{Boletim de}

\section{Estudos Clássicos}

Associação Portuguesa de Estudos Clássicos Instituto de Estudos Clássicos

Coimbra

Dezembro de 2009 


\section{“A DOENÇA MAIS INFAMANTE É A DE INVENTAR HISTÓRIAS": O PROMETEU DE KAFKA}

No caminho onde pisou um deus

há tanto tempo que o tempo não lembra

resta o sonho dos pés

sem peso

sem desenho.

Quem por ali passe, na fração de segundo, em deus se erige, insciente, deus faminto, saudoso de existência.

Vai seguindo em demanda de seu rastro, é um tremor radioso, uma opulência de impossíveis, casulos do possível.

Mas a estrada se parte, se milparte, a seta não aponta destino algum, e o traço ausente ao homem torna homem, novamente.

Carlos Drummond de Andrade, O Deus Mal Informado

Erigi monumento mais perene do que o bronze e mais alto que a real construção das pirâmides, que nem as chuvas erosivas, nem o forte Aquilão, nem a série inumerável dos anos, nem a dos tempos corrida poderão, algum dia, derruir.

Horácio, Ode III, 30.

Sopesadas as coisas, não é justo que Prometeu se queixe dos homens. Ao fim, pelo menos a geração dos poetas honrou-o devidamente. Uma 
compilação como Le thème de Prométhée dans la littérature européenne, de Raymond Trousson, assinala o quanto haveria de desmedida na pretensão de abordar, com o espaço e os recursos de que dispomos, a permanência do tema de uma perspectiva europeia. Concentrar-nos na literatura alemã já seria empresa hercúlea; mesmo focalizando-se apenas o contexto brasileiro, de um herdeiro de Luciano de Samósata que nos apresenta Prometeu em diálogo com Ahasverus, o judeu errante ${ }^{1}$, até prosadores do século XX, como Aníbal Machado, o campo a lavrar é extenso. Por tudo isso, para não correr o risco de incorrer em erro trágico, limitemo-nos, pois, ao Prometeu de Kafka.

O estudo dessa figura vai-se concentrar nos poucos parágrafos do conto Prometheus, intitulado postumamente por Max Brod, em cuja elaboração Kafka teria trabalhado em janeiro de 1918 (PASLEY \& WAGENBACH, 1969: 64). A opção não nos poupa de uma vastíssima fortuna crítica. Não poderia ser diferente, quando nos colocamos diante não só de um dos mais produtivos mitos gregos como também frente a um dos mais representativos autores do século XX. Entretanto, considerados todos os perigos dos penedos alcantilados do mito - constitua-o Prometeu ou o próprio Kafka -, tentaremos apontar algumas características da criação do escritor tcheco. Comecemos com o texto, que é curto e deve nortear nossa reflexão. Nós o apresentamos em tradução de Modesto Carone²:

${ }^{1}$ A intuição de Machado de Assis de vincular as duas personagens (Ahasverus - Viver!, 1886) ocorre igualmente ao estudioso alemão Lovis M. Wambach que, em.Ahasver und Kafka (1993), focaliza na obra do escritor tcheco Ahasverus, o “Eterno Judeu” . De acordo com Wambach, a origem do mito é cristã; no entanto, uma investigação que o vinculasse ao Caim do Antigo Testamento talvez oferecesse interesse. Há elementos comuns do mito de Prometeu também com Adão pela audácia e pela desobediência - para não evocar as similaridades entre Eva e Pandora (segundo Olga Raggio, na transição do paganismo para o cristianismo, Prometeu foi representado como o criador do primeiro homem, às vezes numa prefiguração do Cristo; 1958: 48) —, aproximação que de resto o próprio Kafka pode ter cogitado, já que reflete sobre os dois temas no terceiro caderno in-octavo; com Moisés e Noé por intercederem pelos homens quando sobre eles paira a ameaça do extermínio; com Jó pela punição desproporcional ao erro cometido etc; Kurt Raaflaub (ver referências) traça paralelos, ainda, com a mitologia suméria.

2 Nos cadernos in-octavo, as duas últimas frases abrem o narrado. A alteração da ordem foi proposta por Max Brod e incorporada na maior parte das edições que trazem o texto, incluindo a que adotamos aqui. Esclareça-se, a propósito, que as traduções sem menção são de nossa responsabilidade. 
Sobre Prometeu dão notícias quatro lendas:

Segundo a primeira, ele foi acorrentado no Cáucaso porque havia traído os deuses aos homens, e os deuses remeteram águias que devoravam seu fígado que crescia sem parar.

De acordo com a segunda, Prometeu, por causa da dor causada pelos bicos que o picavam, comprimiu-se cada vez mais fundo nas rochas até se confundir com elas.

Segundo a terceira, no decorrer dos milênios sua traição foi esquecida, os deuses se esqueceram, as águias se esqueceram, ele próprio se esqueceu.

Segundo a quarta, todos se cansaram do que havia se tornado sem fundamento. Os deuses se cansaram, as águias se cansaram, a ferida, cansada, fechou-se.

Restou a cadeia inexplicável de rochas. A lenda tenta explicar o inexplicável. Uma vez que emerge de um fundo de verdade, ela precisa terminar de novo no que não tem explicação ${ }^{3}$. (KAFKA, 2002: 107)

$\mathrm{O}$ primeiro aspecto a ser considerado é que, ainda que se tenha em mente a diversidade de versões do mito, elementos da narrativa são removidos do conto de Kafka e/ou alterados: o logro de Mecona, a astúcia e o roubo do fogo desaparecem; não se explicita de que traição o Titã é acusado; a águia do Pai dos Deuses é multiplicada (e os ofendidos também, uma vez que, pelo menos em Hesíodo e Ésquilo, o confronto direto ocorre apenas com Zeus); suprimem-se os episódios de Oceano e Io e a intervenção salvadora de Heracles; ignora-se mesmo que Prometeu é ele mesmo um deus. Em procedimento que utilizará amiúde, Kafka realiza em profundidade o que descreve na superfície do texto: se a narrativa dirá que resta do entrecho

${ }^{3}$ Von Prometheus berichten vier Sagen:

Nach der ersten wurde er, weil er die Götter an die Menschen verraten hatte, am Kaukasus festgeschmiedet, und die Götter schickten Adler, die von seiner immer wachsenden Leber fraßen.

Nach der zweiten drückte sich Prometheus im Schmerz vor den zuhackenden Schnäbeln immer tiefer in den Felsen, bis er mit ihm eins wurde.

Nach der dritten wurde in den Jahrtausenden sein Verrat vergessen, die Götter vergaßen, die Adler, er selbst.

Nach der vierten wurde man des grundlos Gewordenen müde. Die Götter wurden müde, die Adler wurden müde, die Wunde schloß sich müde.

Blieb das unerklärliche Felsgebirge. - Die Sage versucht das Unerklärliche zu erklären. Da sie aus einem Wahrheitsgrund kommt, muß sie wieder im Unerklärlichen enden. (KAFKA, 1995: 246) 
apenas o rochedo, que podemos interpretar como a base, o substrato fundamental, ele mesmo depura e desbasta, reduzindo o relato a uma síntese lacônica. Isso não deixa de ser, contudo, uma compreensão aguda da natureza do mito, que subsiste na pluralidade de versões, na fusão com outras histórias, na renovação e na permanência.

Um conterrâneo e contemporâneo de Kafka, o escritor Karel Tchápek, utilizaria estratégias bem distintas com um resultado muito diferente, mas apoiado, também, na versatilidade e fecundidade do mito ${ }^{4}$. Não obstante, é curioso que, diferentemente de Tchápek, que desconstrói, mediante personagens mesquinhos e obtusos, a figura gloriosa do doador de todos os dons, Kafka não é seduzido pelos aspectos que conquistarão o homem medieval e o renascentista, o Iluminismo e o Romantismo, Goethe e uma tradição numerosa que chega até Bertolt Brecht e prossegue: estão inteiramente ausentes, em Kafka, a revolta, a arrogância, a independência, o ímpeto criador, o gesto em favor das criaturas, o caráter ambíguo do protagonista... Se, em Hesíodo, o filho de Jápeto domina “a dolosa arte” e, em Ésquilo, ele é copiosamente admoestado por sua loquacidade e descontrole no uso das palavras (nessa direção temos os vv. 180, 311, 326-

${ }^{4}$ Em "O castigo de Prometeu" (Histórias Apócrifas), sob viés cômico, os árbitros Ameteu, Apometeu, Hipometeu e Antimeteu julgam o roubo, suas circunstâncias e conseqüências de múltiplos pontos de vista. Ao fim, Hipometeu retorna, refletindo prosaicamente sobre o poder de cozimento do fogo. Essas cinco versões podem ter ligação com a gênese da narrativa kafkiana, mormente se considerarmos que, no manuscrito original, Kafka menciona existirem 5 versões do mito (BÖSCHENSTEIN-SCHÄFER \& EHRICH-HAEFELI, 1998: 276). Sobre isso, os comentadores divergem. Alguns afirmam que a quinta variante do mito consiste na inexplicável penedo (KREMER, 1998: 32). Para outros, essa quinta vertente está oculta: "There is, however, a fifth, implicit, legend hidden in the text. It says that the birth of the legend of Prometheus itself is due to the presence of the Caucasus rock, which needed explanation; as if people confronted with this phenomenon would need to invent a story to explain it. This would be the legend of the birth of the legend (...).” (KÁLMÁN, 2007: 56) Essa quinta interpretação relaciona-se a algo que, como documenta o historiador Jurgis Baltrušaitis, realmente intrigou os homens ao longo dos séculos, a saber, a existência de formas naturais (árvores, grutas, pigmentação de rochas) que são reconhecidas pelos olhos e pela mente humana como imagens familiares. A esse respeito, conferir a obra Aberrações. 
329, 444, 533...), na releitura de Kafka predomina a solidão e o silêncio ${ }^{5}$. Nem mesmo a ferida fala; eloquente maneira de expressar a incompreensão e o limite humanos face ao mistério (seja ele de que natureza for).

Prometheus surge no contexto de rompimento definitivo com Felice Bauer, de quem o prosador chegou a ficar noivo em duas ocasiões. O relacionamento, cheio de idas e vindas, foi sempre marcado pela irresolução de Kafka e pela sua conviç̧ão de que o casamento sepultaria sua força criativa de modo irrevogável. Tendo em mente que a figura de Pandora, o dúbio dom entregue capciosamente à curta visão de Epimeteu, se entrelaça ao mito do benfeitor dos homens, podemos nos perguntar se o escritor não estaria urdindo, sutilmente, uma trama metaliterária. Essa possibilidade, destacada, entre outros, por Detlev Kremer (1998: 30), vislumbra-se quando lemos duas entradas dos Diários:

9. V. 1912 Como eu, contra toda a perturbação me agarro ao meu romance; exatamente como uma figura de monumento que dirige o olhar para longe e se agarra ao bloco ${ }^{6}$.

6. VI. 1912 Agora leio nas cartas de Flaubert:

Meu romance é o rochedo ao qual eu me agarro e nada sei do que se passa no mundo. - Semelhante ao que registrei em 9 de maio

Sem peso, sem ossos, sem corpo, andei por duas horas pelas ruas e refleti sobre o suportei que hoje à tarde ${ }^{7}$.

5 Na variante kafkiana número 2, Prometeu, premido pela dor, se funde com a rocha (em desenlace que se confunde com o destino da ninfa Eco). O desenvolvimento pelo qual o deus vira Eco, lido como metáfora - o mito se torna resposta e repetição, fragmentando-se e desfigurando-se através do tempo e do espaço - e as ponderações sobre as relações do entrecho com som e linguagem teriam, a nosso ver, interessantes implicações, que, todavia, não podemos abordar no momento. Contudo, ainda sobre isso, lembramos Giovanni Piana, que, comentando o sentido original da palavra "ritmo”, remete o leitor ao verso 241 da tragédia de Ésquilo, no qual o lamento do titã “de curvo-tramar” (expressão que tomo, em português, a Mary Lafer), aludindo às correntes que o aprisionam, poderia ser traduzido por "eu estou aqui preso neste ritmo”. (2001: 175)

6 "Wie ich mich gegen alle Unruhe an meinem Roman festhalte, ganz wie eine Denkmalsfigur die in die Ferne schaut und sich am Block festhält.” Disp. em < http://www.kafka.org/index.php?h6 >, 10 de novembro de 2009.

7 “Jetzt lese ich in Flauberts Briefen: 
A dureza angulosa das pedras e aridez inóspita do cenário pode explicar como, para o escritor, a escrita, mesmo sendo considerada uma vocação inescapável (mais tarde, Kafka vai personificar a Literatura, dizendoa sua "terrível esposa ${ }^{8}$ ”), se revestia de dificuldades e obstáculos dolorosos. E, de fato, é fácil constatar que, em diversos momentos da correspondência com Felice, Kafka tentou provar à secretária berlinense que sua atividade criativa seria incompatível com a vida conjugal.

Em 1923, pouco antes de morrer, Kafka, em carta a outra de suas amadas, a jornalista e tradutora Milena Jesenská, trata da concorrência que o lado humano e perecível do poeta faz, enquanto ele vive, ao traço imorredouro que as grandes obras inscrevem na rocha do tempo. Parece, então, assaz lógico que o rochedo, equiparado senão à escrita, ao menos à obra literária, seja o único vestígio a permanecer intacto:

Isto pode explicar-se através da minha teoria de que escritores vivos têm uma conexão viva com os seus livros. Eles lutam, pela simples existência, por ou contra eles. A verdadeira vida independente do livro começa apenas depois da morte do homem ou, mais exatamente, um período depois da morte, porque esses homens enérgicos lutam ainda um instantinho além da morte por seu livro. Depois, todavia, este é afastado da convivência e pode abandonar-se apenas à força das batidas do próprio coração ${ }^{9}$.

O enlace dos mitos não é mais exclusivo; além de Eco — pois que, pelo sofrimento, o corpo se desfaz, sem ossos e sem peso, tal qual na entrada do Diário, unicamente na voz - , convoca-se, pelo ato paciente de aos poucos tornar-se pedra, a Medusa, que será, em mais de uma oportunidade, eleita

Mein Roman ist der Felsen, an dem ich hänge und ich weiß nichts von dem was in der Welt vorgeht. -Ähnlich wie ich es für mich am $9 \mathrm{~V}$ eingetragen habe

Gewichtlos, knochenlos, körperlos zwei Stundenlang durch die Gassen gegangen und überlegt, was ich nachmittag beim Schreiben überstanden habe.” Disp. em < http://www.kafka.org/index.php?h6 >, 10 de novembro de 2009.

8 Nas Cartas a Milena: schreckliche Ehefrau (KAFKA, 1997: 214).

9 “Es ist das durch meine Teorie zu erklären, daß lebende Schriftsteller mit ihren Büchern einen lebendigen Zusammenhang haben. Sie kämpfen durch ihr bloßes Dasein für oder gegen sie. Das wirkliche selbstständige Leben des Buches beginnt erst nach dem Tod des Mannes oder richtiger eine Zeitlang nach dem Tode, denn diese eifrigen Männer kämpfen noch ein Weilchen über ihren Tod hinaus für ihr Buch. Dann aber ist es vereinsamt und kann nur auf die Stärke des eigenen Herzschlags sich verlassen.” (KAFKA, 1997: 315) 
como a imagem fiel da mulher da qual, contra a vontade do vencido, se é prisioneiro. "Deves, em cartas tais, ter a grandiosa cabeça da Medusa, a tal ponto convulsionam-se as serpentes do horror em torno de tua cabeça e da minha as ainda mais selvagens serpentes do medo" ${ }^{10}$, é o que conclui o escritor, apavorado ante o poder que outro ser pode ter sobre ele. Nesse sentido, antes de ser dissolução ou desfiguração do mito, seria, como propôs Hans Blumenberg (apud KREMER, 1998: 34), uma mitologização da história da recepção da narrativa mítica. Ou, ainda, da busca, em vida, de viver como um morto para assim alcançar a imortalidade.

\section{Referências}

ANDRADE, Carlos Drummond de. O deus mal informado. Antologia poética. Rio de Janeiro: José Olympio Editora, 1980. p. 246.

BALTRUSAITIS, Jurgis. Aberrações. Trad. Vera Azambuja Harvey. Rio de Janeiro: UFRJ, 1999.

BARBOSA, Tereza Virgínia Ribeiro. Notas para encenação de Alceste, Ifigênia em Áulis e Prometeu. O Corpo em performance. HILDEBRANDO, Antonio, NASCIMENTO, Lyslei. e ROJO, Sara. (orgs). Belo Horizonte: Nelap/Fale-UFMG, 2003. pp. 145-170.

CANETTI, Elias. O outro processo - As Cartas de Kafka a Felice. Trad. Herbert Caro. Rio de Janeiro: Espaço e Tempo, 1988.

ÉSQUILO. Prometeu agrilhoado. Introd., trad. do grego e notas de Ana Paula Quintela Sottomayor. Lisboa: Edições 70, 1992.

GIBIAN, George. Karel Capek's Apocrypha and Franz Kafka's Parables. American Slavic and East European Review, Vol. 18, No. 2. (Apr., 1959), pp. 238-247.

HESÍODO. Os trabalhos e os dias. Trad., introd. e coment. Mary de Camargo Neves Lafer. São Paulo: Iluminuras: 1996.

. Teogonia. Trad., introd. e coment. Jaa Torrano. São Paulo: Iluminuras: 1991.

HORÁCIO. Ode III, 30. In: Odes e Epodos. Anna Lia Amaral de Almeida Prado (org.). Trad. Bento Prado de Almeida Ferraz. São Paulo: Martins Fontes, 2003. p. 141.

10 “Du mußt in solchen Briefen den großartigen Kopf der Medusa haben, so zucken die Schlangen des Schreckens um Deinen Kopf und um meinen allerdings noch wilder die Schlangen der Angst.” (KAFKA, 1997: 59). 
KAFKA, Franz. Briefe an Milena. Her. Jürgen Born und Michael Müller. Frankfurt am Main: Fischer Taschenbuch Verlag, 1997. . Erzählungen. Stuttgart: Philipp Reclam, 2003. . Narrativas do Espólio. Trad. e posfácio de Modesto Carone. São Paulo: Companhia das Letras: 2002.

KÁLMÁN, György C. Kafka’s Prometheus. Neohelicon, XXXIV (2007), 1, pp. 51-57.

KREMER, Detlev. Kafka: Die Erotik des schreibens. Bodenheim beim Mainz: Philo, 1998.

PASLEY, Malcolm und WAGENBACH, Klaus. Datierung sämtlicher Texte Franz Kafkas. BORN, Jürgen. et al. Kafkas Symposion. München: Deutscher Taschenbuch Verlag, 1969.

PIANA, Giovanni. A Filosofia da Música. Trad. Antonio Angonese. Bauru: EDUSC, 2001.

RAAFLAUB, Kurt. Enki e Prometeu: o herói de cultura no mito e pensamento da Mesopotânia e da Grécia. Trad. Adriano Scatolin. Letras Clássicas, ano 6, $n^{0}$ 6. São Paulo: Universidade de São Paulo, 2002. pp. 1123.

RAGGIO, Olga. The Myth of Prometheus: Its Survival and Metamorphoses up to the Eighteenth Century. Journal of the Warburg and Courtauld Institutes, Vol. 21, No. 1/2 (Jan. - Jun., 1958), pp. 44-62.

SANTINI, Daria. Antike Mythen: Kafka und Brecht, by Frank D. Wagner (review). Modern Language Review, 102, 4. Cambridge: Cambridge University Press, oct. 2007. pp. 1186-1187.

SÉCHAN, Louis. Le Mythe de Prometheé. Paris: Presses Universitaire de France, 1958.

SOARES, Carmen Isabel Leal. Prometheus Desmotes: um "olhar” no Titã. Humanitas, vol XLVII, tomo I. Coimbra: Universidade de Coimbra, 1995. pp. 81-95.

SOTTOMAYOR, Ana Paula Quintela. Prometeu em Vila Nuvem dos Cucos (Av. 1494-1552). Humanitas, vol XLVII, tomo I. Coimbra: Universidade de Coimbra, 1995. pp. 233-240.

STADLER, Ulrich. Subversive Arbeit am Mithos: Kafka’s Beziehung zur Antike und die fünf "Sagen" von Prometheus. In: BÖSCHENSTEINSCHÄFER, Renate und EHRICH-HAEFELI, Verena. Antiquitates Renatae: deutsche und französische Beiträge zur Wirkung der Antike in der europäische Literatur. Würzburg: Königshausen und Neumann, 1998. pp. 271-284. 
TCHÁPEK, Karel. Histórias Apócrifas. Trad. Aleksandar Jovanovic. Rio de Janeiro: Ed. 34, 1994.

WAGNER, Frank Dietrich. Antike Mythen: Kafka und Brecht. Würzburg: Königshausen und Neumann, 2006.

WAMBACH, Lovis M. Ahasver und Kafka: zur Bedeutung der Judenfeindschaft in dessen Leben und Werk. Heidelberg: Winter, 1993.

MANUELA BARBOSA 